Revista Iberoamericana, Vol. LXXVII, Núms. 236-237, Julio-Diciembre 2011, 953-973

\title{
NO HAY RELACIÓN SEXUAL: LA VOZ QUA ANGUSTIA DE ESTEBAN ECHEVERRÍA EN CARTAS A UN AMIGO
}

\author{
POR \\ Martín Sorbille \\ University of Florida
}

Luchó, sin embargo, por levantarse porque se oía cada vez con mayor intensidad la enigmática y remota voz que lo llamabay (ahora lo advertía) que lo llamaba con ansiedad, como si estuviera en un pavoroso peligro y él, solamente él, fuese capaz de salvarla. Despertó estremecido por la angustia y casi saltando del asiento. Era ella.

Ernesto Sábato, Sobre héroes y tumbas

\section{Problema y tesis}

Es sorprendente que la narración seudo autobiográfica-epistolar Cartas a un amigo (escrita entre 1830-1836 y publicada en 1873) de Echeverría siga siendo ignorada por la crítica especializada, ${ }^{1}$ cuando ésta es uno de los pilares estructurales de los temas

\footnotetext{
1 El hecho que las Cartas a un amigo hayan sido desestimadas por la crítica se debe principalmente a dos motivos: a) carecen de valor literario y b) se descree de la veracidad de su contenido autobiográfico.

a) Si bien es cierto que Cartas no ofrecen ningún aporte estético, sí son valiosas por ser posiblemente el primer texto seudo epistolar argentino escrito en vida independiente y por el eclecticismo de su composición: el contexto autobiográfico amalgamado a una ficción de características oníricas y a las representaciones y observaciones biológicas-naturalistas de las pampas argentinas convierte a Cartas en una obra original en sí misma a la vez que anticipatoria de temas y tipologías que serán evocadas en el trío La cautiva (1837) -Dogma socialista (1839)- "El matadero" (redactado entre 1839-1840 y publicado en 1871). Por ejemplo, el final trágico de María en La cautiva es el mismo del personaje María en Cartas: las dos Marías enloquecen cuando sus amados mueren luchando en la frontera. Mientras que en Cartas somos informados que: "María ha perdido la razón" (Obras completas 531); en La cautiva leemos que: "una a una, todas bellas,/ sus ilusiones volaron,/ y sus deseos con ellas;/ sola y triste la dejaron/ sufrir hasta enloquecer" (IX, v. 287-91). Esta relación entre ambos desenlaces no sólo evidencia que Cartas es un primer borrador de La cautiva sino que, mucho más importante aún, contradice la tesis canonizada y difundida hasta ahora por toda la crítica especializada por la cual habría una falta de coherencia argumental en el poema; a saber: ¿cómo es posible que María primero afirme que su hijo está muerto y luego que está vivo? Pues bien, si se tiene en cuenta que María enuncia estas últimas palabras luego de haber atravesado el ardiente e inmenso desierto y, por sobre todo, después de que la muerte de su
} 
héroe romántico implicase la pérdida de su deseo en sí, entonces es perfectamente lógico que ella quede despojada de su condición humana hasta "enloquecer".

b) Siguiendo esta lógica desirativa, Cartas está revelando que el deseo fantasmático singular de Echeverría reaparecerá plasmado en la construcción de los héroes románticos de La cautiva-Dogma socialista- "El matadero": Echeverría se proyecta fantasmáticamente como Brian, María, el unitario y los héroes históricos redimidos y glorificados primero en Dogma socialista y luego en el ensayo Ojeada retrospectiva (1846) que le precederá a la reedición de Dogma.

Lo poco publicado sobre Cartas se centra casi exclusivamente en la veracidad o verosimilitud de su fondo autobiográfico. La conclusión de Beatriz Sarlo, Carlos Altamirano, Adriana Amante y Jorge Myers (los únicos críticos que escuetamente han interpretado a Cartas) es más o menos ésta: si el contenido es un invento, entonces hay que descartar el texto por completo. Por ello la intención ha sido descubrir la prueba irrefutable de su falsedad o por lo menos sembrar serias dudas para, por extensión, deslegitimarlo como biográfico. Mientras que Sarlo y Altamirano sostienen que "estos textos 'autobiográficos' (que, en verdad, lo son de manera muy dudosa)" (33), Myers es más enfático al establecer que "generaciones enteras de críticos han sido engañados por la presuposición errónea de Gutiérrez de que se trataba de un texto autobiográfico y no una ficción" (Myers 63, énfasis mío).

En efecto, el hecho que su amigo y primer biógrafo, Juan María Gutiérrez, haya incluido a Cartas en la sección de "Apuntes autobiográficos" en las Obras completas que él editó, junto a otros escritos que sí son claramente autobiográficos, marcó irreversiblemente sobre la piel de Cartas la insignia que la nombrará para siempre. Por consiguiente, medido contra la acepción tradicional de la autobiografía epistolar, es fácil encontrar las falencias que desvían a Cartas de su supuesta categorización. Para peor, la controversia sobre la veracidad de Cartas fue agravada por algunos de los primeros críticos que no cuestionaron el tiempo que sugieren las fechas incompletas de Cartas o incluso, como Natalio Kisnerman, llena este vacío con su propia letra (en el prólogo de su edición titulada Páginas autobiográficas, Kisnerman escribe: "hemos salvado errores [...] modificando algunas fechas" 6).

Además, el escepticismo aumenta exponencialmente cuando ha de notarse que: a) el lenguaje hiperbólico para su madre se asemeja al de un enamorado, b) no hay correspondencia cronológica entre la biografía de Echeverría y el contenido de Cartas y c) el formato de Cartas revela la influencia de textos publicados una década después de las fechas aludidas; entre otros, Le Lac y Destinées de poésie (1834) de A. Lamartine y Las penas del joven Werther (1774) de J. W. Goethe que Echeverría no había leído hasta su desembarco en Francia en 1826. Sobre este último Amante destaca que se ponen en práctica los asuntos que ya habían sido cristalizados en Las penas del joven Werther: "la consustanciación del yo con la naturaleza, la melancolía, los quebrantos de salud ligados a la nostalgia, la misantropía del héroe, algún ensueño registrado en clave gótica, la tentación del suicidio" (Amante 488) y Myers afirma que: "la estructura general, la trama, y el entramado filosófico-estético corresponden a la novela de Goethe" (Myers 62).

Es cierto que Las penas habrá influido en la construcción de Cartas por las razones mencionadas y también por las estrategias narrativas que comparte como, por ejemplo, el ocultamiento de la identidad de los personajes y los síntomas psicosomáticos de algunos de ellos. No obstante, la apropiación de elementos del argumento y formato de la historia de Goethe está lejos de ser un plagio, ya que Echeverría pivotea todo el argumento de Cartas en torno a la muerte de la madre; y este aspecto crucial de la trama que posibilita que la angustia que siente el 'personaje' Echeverría sea el eje de la estructura de Cartas, no lo encontramos en Las penas. Entonces, si desechamos la suposición que la esencia de Cartas es una argentinización de la novela alemana, también tenemos que problematizar la hipótesis que Cartas no sea autobiográfica.

Lo que estoy sugiriendo es que aunque el lenguaje hiperbólico, la estética y la discrepancia cronológica hacen dudar sobre su veracidad, esto no significa que Cartas sea "una ficción" de "dudosa" sinceridad.

Revista Iberoamericana, Vol. LXXVII, Núms. 236-237, Julio-Diciembre 2011, 953-973 ISSN 0034-9631 (Impreso) 
clave de sus coetáneos La cautiva, Dogma socialista y "El matadero":2 Cartas revela los antagonismos reprimidos de su creador, que luego plasmará negativamente en la construcción del sacrificio de su héroe romántico y que obedecen al lado masoquista de su 'fantasma', constituido con y por el fallecimiento de su madre en $1822 .{ }^{3}$ Con precisión, Cartas patentiza la culpa qua angustia en forma de 'voz flotante' que lo atormenta por haberle causado su muerte y lo arrastra hacia su propio sacrificio como único escape. Así como Abrahán iba a sacrificar la vida de Isaac porque lo angustiaba no saber lo que Yahvé deseaba de él, Echeverría pretende sacrificarse para no ser arrollado por la

Cartas sí es un texto autobiográfico no sólo porque está refiriendo a hechos históricos-reales indisputables sino, más importante aún, porque, como se verá, contiene su singular deseo fantasmático inconsciente inscripto negativamente en la superficie positiva.

En tal orden, es más lógico suponer que desde el presente 1830-1836, Echeverría está 'novelizandofantasmatizando' retroactivamente el origen de su condición de poeta-intelectual que él le atribuye al evento de la muerte de su madre, reflejando así la estructura madre de los fantasmas originarios/primarios de todo sujeto (los protofantasmas universales de los que derivan los múltiples fantasmas particulares). Un procedimiento que de hecho vuelve a reciclar una década después cuando debe exiliarse en Uruguay: en su condición de abandonado (sin el reconocimiento del que gozaba entre la intelectualidad porteña) y con serios problemas económicos y de salud, Echeverría publica Ojeada retrospectiva para resucitar a la Asociación de la Joven Generación Argentina de 1838, que el presidía, porque así está retrofundandoremitificando a la Asociación y a sí mismo.

Retomando la lógica de su deseo inconsciente, lo más importante de acentuar de la relación de Cartas con Las penas es preguntarse ipor qué eligió esta novela y no otros textos como espejo en el cual reflejar a Cartas? Que Las penas atraiga el deseo de Echeverría significa que hay algo en ese texto que se corresponde con su fantasma; en Las penas Echeverría está reconociendo su objeto fantasmático causante de su deseo. No es poca cosa que varios aspectos del argumento de Las penas coinciden con las circunstancias de la vida de Echeverría (la ausencia del padre de Werther, su asistencia a los bailes de la burguesía para enamorar a Lotte y, por sobre todo, la 'no-relación' que mantiene Werther con su madre). Lo mismo podemos decir de otros protagonistas echeverrianos: si sus héroes están moldeados sobre los de Byron, es porque Echeverría reconoce inconscientemente algo en ellos que ya habitaba en lo (su) inconsciente -por eso los (re)conoce- o de lo contrario simplemente se habría inspirado en otros arquetipos para la construcción de los suyos. Se entiende así por qué Cartas, los héroes románticos y el contenido de muchas de sus obras no son meramente el reflejo del Romanticismo. Si el sujeto fuese una construcción de la cultura-ideología dominante, entonces carecería de subjetividad, sería un disco duro ya programado. Por eso hay que distinguir entre una construcción-identidad imaginaria en continua rearticulación y una construcción fantasmática inconsciente firmemente arraigada y muy difícil de cambiar. Véase la sección V.

$\mathrm{Al}$ menos que se indique lo contrario, todas las citas de Echeverría corresponden a la edición de las Obras completas; además, ellas reflejarán la ortografía del original.

2 Cartas adelanta los temas clave de los tres textos echeverrianos; a saber, a) civilización versus barbarie, b) la exaltación al sacrificio por los ideales de la Revolución de Mayo y c) el martirio del héroe como evento necesario para regenerar a una sociedad desviada de los ideales independentistas, es decir, provocar un efecto de culpa en la conciencia colectiva para que se revierta a su antítesis a partir de la identificación con la ideología del héroe; en términos análogos a la fundación del Cristianismo: la muerte del mártir como nacimiento de la civilización europea-argentina.

3 Para una explicación teórica de la relación entre los personajes literarios y su creador, consúltese "Writers and Day-Dreaming" (1908) de Sigmund Freud.

Revista Iberoamericana, Vol. LXXVII, Núms. 236-237, Julio-Diciembre 2011, 953-973
ISSN 2154-4794 (Electrónico) 
indescifrabilidad del deseo de su madre que, en carácter de espectro persecutorio, busca vengar su muerte biológica.

O sea que, en términos psicoanalíticos, ella no ha muerto simbólicamente ya que retorna 'fantasmáticamente' desde y en 'lo Real' como voz en los sueños y en la vigilia de Echeverría para increparle que todavía hay algo traumático en la relación que no ha sido resuelta, simbolizada. La madre 'no-muerta' (no está viva ni muerta sino suspendida en el espacio de los 'muertos vivos') personifica la pulsión de muerte que retorna incesantemente para, como si estuviese revirtiendo la historia, regresar a su hijo al mismo estado pre-ontológico, de puro goce, en donde ella vive como no-muerta. Echeverría es acosado por la angustia de ser, en vida, 're-infetado' al vientre de la madre 'siniestra', a vivir eternamente en el submundo de los muertos.

Sobre los cimientos de la contraintuitiva pero rigurosa lógica de Sigmund Freud, Jacques Lacan y las elucidaciones de sus intérpretes, los teóricos-filósofos Slavoj Žižek, Mladen Dolar y Alain Juranville, el objetivo de este trabajo es positivizar la negatividad del deseo fantasmático de Echeverría que habita en Cartas y que este mismo discurso está reprimiendo, negando; positivar la 'falta' en el lenguaje, la voz que es el deseo incestual en sí. En tal sentido se rompe con la perspectiva historicista que reduce el campo social a una red de relaciones positivas de poder y saber activadas por causas inmanentes: se analizará la relación del fenómeno en su apariencia (Cartas) con su causa no-inmanente que, porque ha generado el fenómeno, es portada por el fenómeno sin que sea discernible en su apariencia. ${ }^{4}$ Una 'causa' que no es del orden de la ley, de la cadena simbólica (de que algo simbólico ' $x$ ' ha determinado algo simbólico ' $y$ '), sino de una dimensión negativa, pre-simbólica, sexual, Real, que hace marchar el deseo simbólico, pero sin estar materializada en su superficie positiva. Como sucede con una

4 Parafraseando a Joan Copjec, la diferencia fundamental entre la posición adoptada por las varias teorías historicistas, incluyendo la psicología, y la del psicoanálisis es la siguiente: mientras que aquellas entienden al sujeto como una alforja de experiencias vivenciadas (aunque no las recuerde) y, por lo tanto, en la medida en que estas experiencias (positivas) puedan ser recreadas, se estaría armando el rompecabezas temporal (la verdad qua historia), para el psicoanálisis el sujeto es afectado en continuo por la distorsión metafórica y metonímica que sufre el significante, incluyendo sus rupturas internas, es decir, por una realidad psíquica que no se vivencia como tal (como experiencia positiva) ni habrá de recordarse. Copjec explica en Read My Desire, Lacan Against the Historicists (1994): "This does not mean that psychoanalysis renounces history to mantain a truth that no history can uncover. Psychoanalysis requires history; it can begin only by gathering the facts. What it renounces is what we can now term the "historicist" construction. Historicism is faulted not because it is, in fact, not possible to recreate historical experience [...], but because this construction operates with the belief that it is experience that must be recreated, that the truthful and logical statements we make about a historical period are empirical generalizations about the ways in which people thought $[\ldots]$ we know now $[\ldots]$ what goods men and women of various classes were supposed to find pleasurable, which of these were denied them, which allowed, and how the inequalities in the distribution of goods affected the actions of these men and women. We learn nothing, however, of the historical effects of the fact that men and women often act to avoid pleasure, to shun these goods" (68).

Revista Iberoamericana, Vol. LXXVII, Núms. 236-237, Julio-Diciembre 2011, 953-973 ISSN 0034-9631 (Impreso) 
fotografía, si hay una representación positiva tuvo que haber existido una causa que la generó: su negativo. ${ }^{5}$

Por ende las siguientes páginas no pretenden: 1) 'aplicar' ortodoxamente la teoría freudiana-lacaniana al objeto de estudio (la manera en cómo las diversas corrientes psicológicas continúan mal interpretando a Freud e insisten en enfocarse pura y exclusivamente en los registros Imaginario y Simbólico -el carácter positivo del significante-e ignorar por completo a lo Real), 2) deducir la 'psicología' de Echeverría desde Cartas (localizar su biografía en la obra), por lo cual el texto sería una mera reflexión del yo/ego del autor, o 3) interpretar jungianamente su 'personalidad' a partir del arbitrario valor simbólico que se le adjudica a los objetos asociados a él ("el tigre del sueño simboliza...", "el color rosa de su vestimenta prueba/representa..."). Por el contrario, la finalidad de este ensayo es proporcionar una 'construcción' no-platónica de la causa negativa-Real en el corazón mismo del fantasma de Echeverría. ${ }^{6}$

En sintonía con los fundamentos psicoanalíticos elucidados por Freud en "Constructions in Anaylisis" (1937), "A Child is Being Beaten" (1919) y "Leonardo da Vinci and a Memory of His Childhood" (1910), y puestos a punto por Lacan en su Seminario La angustia (1962-1963), en este estudio se intentará: a) teorizar qué es Cartas y cuál es la causa del sufrimiento del 'personaje' Echeverría y b) evidenciar cómo la voz qua traumático Real está ligada a la defunción de su madre, sus pesadillas y su intento de suicidio; es decir, cómo la voz fustigadora-ejemplificada perfectamente

5 ¿O es que acaso recordamos con exactitud todos los significantes de nuestros primeros cinco años y cómo cada uno de ellos nos afectó y persiste afectándonos? ¿Y no es lógico asumir entonces que éstos han moldeado nuestro deseo, el cual nos gobierna sin que seamos conscientes del por qué? Y, por ende, ¿no estaría 'la causa' del deseo inconsciente inscripta negativamente en nuestras acciones?

6 Y debido a que durante décadas casi todas las interpretaciones de Freud y Lacan omitieron el orden Real constitutivo del sujeto (objet petit a), fue fácil para la clásica crítica posestructuralista angloamericana localizar, en estas interpretaciones, sus falencias lógicas que de inmediato, por error, fueron atribuidas a Freud y Lacan. De ahí que, por ejemplo, hasta hace muy poco -hasta que principalmente el filósofo y psicoanalista Slavoj Žižek hizo sonar la alarma sobre las desviaciones de los principios freudianoslacanianos manejados por la academia y hasta la retrofundación de los conceptos psicoanalíticos alrededor de lo Real- imperaba la prédica de la "muerte del autor barthesiana" y se daba por debatido y superado analizar al autor a partir de su obra. En efecto, el autor está muerto pero sólo si se concibe al autor como un "yo". Pero como Freud y Lacan insistieron desde un comienzo, el sujeto no es el yo.

Vale aquí hacerse una pregunta: si el texto no es del autor (o "scripteur"), ¿entonces de quién es? Sucede que el sujeto emerge de forma singular en los intersticios vacíos de y en el lenguaje, en las condensaciones y desplazamientos singulares de los significantes, en cómo está singularmente inserto en el orden diferencial del significante, en cómo operan sus fantasmas 'singulares' en relación al deseo del Otro. Son estas fracturas y rupturas contenidas negativamente en el texto aquéllo que podría permitir un acercamiento al fantasma del autor, especialmente cuando se trata de una autobiografía ficcionalizada como lo es Cartas. Si el síntoma 'es' el sujeto, es decir, si el síntoma es sus múltiples fantasmas singulares condensados en una inconsciente exteriorización corporal -la forma singular en cómo el sujeto (ex) iste en la realidad, evitando así caer en la psicosis-, el texto es entonces, por definición, una expresión síntomática y singular del autor. Véanse la nota 7 y la sección III.

Revista Iberoamericana, Vol. LXXVII, Núms. 236-237, Julio-Diciembre 2011, 953-973
ISSN 0034-9631 (Impreso) 
por el contenido y título del epígrafe que encabeza este ensayo- realiza su fantasma de ser 'un mal parido' y es la causa de que en Cartas 'no hay relación sexual'?

La importancia de ahondar en estas cuestiones radica en que -dado que Cartas evidencia más claramente la fantasmatización de Echeverría presente también en $\mathrm{La}$

La argumentación de la 'construcción' retroactiva de lo Real del fantasma es semejante a la lógica de la física cuántica iniciada por Werner Heisenberg. Por ejemplo, no es posible medir simultáneamente la posición y la velocidad del electrón durante la manifestación del fenómeno sino a posteriori, cuando éste ya es el pasado (en parte porque el mismo acto de medir la velocidad afecta a la velocidad). Sólo entonces, al contar con la información del presente, que en el tiempo inmediatamente anterior al fenómeno aún no existía porque era un futuro conjetural, es viable aprehender retroactivamente la velocidad y la posición del electrón. El pasado existe como cálculo lógico (no-empírico) retroactivo, habrá sido, porque ahora existe un presente contra qué medirlo y desde dónde medirlo. Durante el fenómeno el saber era imposible (o la velocidad o la posición, pero no ambos), luego el saber se convierte en una fórmula retroactiva, es decir, sigue siendo imposible saberse con certeza la verdad del fenómeno. Freud ejemplifica esta lógica en "A Child is Being Beaten" y "Leonardo da Vinci and a Memory of His Childhood".

Freud siente que la razón por la que muchos de sus pacientes confesaban con vergüenza y sentimiento de culpa que en su infancia gozaban fantasmatizando una escena en la cual observaban a un niño siendo pegado por una figura representativa de la ley del padre era porque tuvo que haber habido dos fases previas a la forma final del fantasma confesado. Mientras que la primera fase de carácter sadista era difusamente recordada sobre la base de detalles de distintas escenas, la segunda fase de orden masoquista era totalmente inconsciente, nunca exteriorizada simbólicamente por el paciente. No obstante, Freud deduce que la segunda fase es el ancla de la realidad psíquica del fantasmatizador porque es el trauma reprimido que actúa como causa de su deseo materializado como primera y tercera fase. La segunda fase es lo Real; el negativo imperceptible en la fotografía que posibilita su imagen positiva. Así como la ausencia del negativo (gestado por la acción simbólica de apretar el dispositivo de la cámara) imposibilita la existencia de la fotografía, la falta de lo Real (constituido por el mismo proceso metafórico y metonímico del lenguaje, de lo Simbólico) desintegraría la construcción fantasmática; el sujeto dejaría de ser sujeto del, y al, lenguaje. La construcción no-historicista de la segunda fase posibilita una explicación lógica de la condición sadomasoquista de todo ser humano.

Y en "Leonardo da Vinci and a Memory of His Childhood" Freud resuelve que el enigma del carácter de da Vinci sobre su sexualidad inactiva u homosexualidad y su conversión en pulsión del saber fue causado por un fantasma, "el fantasma del buitre". El psicoanalista descubrió en un cuaderno autobiográfico del pintor que el recuerdo de cuna de un buitre que desciende hacia él para abrirle la boca y darle con la cola en los labios es la repetición de una situación que se remonta a la etapa de lactancia (82-87). El buitre se asocia al pecho de la madre por una cuestión orgánica (la cola de buitre le proporciona el mismo goce que el pezón de la mamá) y por la relación visual-homofónica de la imagen del buitre en la civilización egipcia con la palabra madre. Debido a esta asociación de significantes y a que Da Vinci era hijo ilegítimo criado por su madre, Freud concluye que las sonrisas de la Mona Lisa y de otras mujeres en sus pinturas eran la de su madre y que las cabezas bellas de los niños son "reproductions of his own person as it was in childhood" (111). La tesis de Freud es luego refutada por varios historiadores del arte que demuestran fácilmente que la palabra nibbio en italiano no significa buitre (Geier en alemán) sino milano. Es decir, Freud había montado parte de su teoría sobre una errónea traducción del cuaderno de Da Vinci al alemán. No obstante, no hay que descalificar por completo la tesis de Freud, ya que en 1987 un análisis computarizado de la Mona Lisa probó científicamente que la cara de la mujer sentada corresponde al contorno facial de Leonardo. Por consiguiente, la cabeza bella es, como sostenía Freud de sus otros cuadros, un autorretrato de su creador.

Revista Iberoamericana, Vol. LXXVII, Núms. 236-237, Julio-Diciembre 2011, 953-973
ISSN 0034-9631 (Impreso) 
cautiva-Dogma-"El matadero" y por el hecho que esta triada canónica es constitutiva de las letras y la cultura del país austral- el análisis de la no-relación de Echeverría con su madre materializada como voz-Real está invitando a la reformulación de los orígenes de la identidad nacional: si los conflictos mentales de Echeverría están presentes en la La cautiva-Dogma-“El matadero", ellos estarían alojados, correspondientemente, en las entrañas de la cultura argentina. ${ }^{8}$ A modo de analogía: al igual que la autobiografía

8 Parte de la crítica pasa por alto que a) a través de la terna poesía-ensayo-narrativa, Echeverría y no Domingo Sarmiento sigue siendo el sostén primario de la realidad argentina y de sus múltiples interpretaciones; $y$, la crítica toda ha desapercibido que b) como se anticipa en la nota 2, estos tres textos también materializan a la voz-Real o su efecto angustiante en los personajes.

A) En primer lugar La cautiva le dio vida ontológica a la oposición 'civilización versus barbarie' cuyo objetivo fue imponer un orden capitalista en el desierto pampeano. Esta reducción binaria continúa predominando en el imaginario colectivo argentino. Si hoy en día el conflicto se centra en 'el campo versus el gobierno', antes lo fueron, por ejemplo, 'la reorganización nacional militar o la subversión', 'la capital federal o el peronista del interior', 'el patriotismo argentino o el anarquismo extranjero' y 'la civilizada ciudad o el salvaje campo del gaucho federal' del Facundo (1845) de Sarmiento.

De hecho el manifiesto político Dogma es uno de los pilares del último capítulo del Facundo y del contenido de las Bases (1852) J. B. Alberdi, que es la matriz de la vigente Constitución Argentina de 1853, máximo recurso para avanzar en el territorio nacional el capitalismo y los valores de la modernidad que lo acompañan.

¡Y qué decir de "El matadero"! ¿No es hasta el día de hoy la metáfora por excelencia de la violencia que ha venido azotando a la sociedad argentina desde, con y por su nacimiento? ¿No son las múltiples expresiones artísticas emuladoras de "El matadero" la prueba de que se ha convertido en el ancla de la cultura argentina? ¿No ha sido "El matadero" reconfigurado por escritores de la talla de Borges y Bioy Casares ("La fiesta del monstruo", 1955) u Osvaldo Lamborghini ("El niño proletario", 1973) para denunciar, desde sus respectivas posiciones ideológicas, la supuesta barbarie de la oposición política? ¿No está el título de la revista El Matadero: Revista Crítica de Literatura Argentina (1998-presente), dirigida por David Viñas y Marcela Croce, aludiendo al "El matadero" como centro de gravedad de la literatura-cultura argentina?

B) En "El matadero" la voz se 'presentifica' a lo largo del relato en forma de ruidos constantes, gritos, enunciados imperativos, imprecisos, entrecortados, intervenciones disonantes, etc.: "oír tanta batahola de imprecaciones" (430), "donde millares de voces, conjurando" (430), "grandes vociferaciones y palmoteos" (432), "desaforados gritos" (432), "gritería descompasada" (434), "palabras inmundas y obscenas, vociferaciones preñadas de todo el cinismo bestial" (435), "gritos y puteadas" (435), "groseras carcajadas y gritos frecuentemente" (435), "y era de oír la desonante batahola de silbidos, palmadas y voces tiples y roncas que se desprendía de aquella singular orquesta" (435-36), "El tropel y vocería era infernal" (437), "voz imperiosa" (438), "voz ruda" (438), "ronca voz" (438), "vociferaciones e injurias" (440), etc. Es decir, la voz-Real se presentifica en su función de obstructora de las leyes religiosas y federales; la voz-Real que impide la materialización de la ley simbólica. Véanse la sección IV y las notas 13 y 14.

Es precisamente por esta razón que Brian y María en La cautiva y los personajes históricos en Dogma, como Abrahán en el Antiguo Testamento, tienen que simbolizar el deseo indescifrable del Otro en forma de voz-Real haciendo el pasaje al acto. Para poder apaciguar la angustia insoportable, completan el sinsentido de la voz-Real con el enunciado que es el sacrificio para el Otro personificado por Dios o los Ideales de Mayo respectivamente.

En otro trabajo en preparación analizo la condición Real de la voz en las tres obras.

ISSN 0034-9631 (Impreso) 
de Daniel Paul Schreber, Memoirs of My Nervous Illness (1903), le permitió a Freud confeccionar su teoría de la paranoia en relación al despotismo del padre de Schreber, a Elias Canetti a vincular las fantasías paranoicas de Schreber con la paranoia de Adolf Hitler, y a Eric Santner a entrelazar las crisis de Schreber desencadenante de su psicosis con las crisis de la modernidad causantes del plan nazi y su solución "final" a estos desbarates sociales; una nueva aproximación a la subjetividad de Echeverría a partir de la autobiografía Cartas puede abrir el espacio, en el año del Bicentenario, para una reinterpretación de la modernidad argentina. ${ }^{9}$

\section{Aspectos Significativos de CARTAS}

Cartas es un compendio de treinta cartas que Echeverría le escribe a un presunto destinatario por motivo de la enfermedad y eventual muerte de su madre. La aflicción de Echeverría no deviene meramente de la tragedia, sino de su culpa por la misma. ¿Por qué? Porque, según las palabras de Echeverría, la melancolía mortal de la madre fue causada por su comportamiento escandaloso: su concurrencia a lugares indebidos y su relación amorosa con una mujer casada supuso un golpe emocional muy duro para Doña Martina Espinoza. ${ }^{10}$ ¿Cuál fue la razón de su 'mala' conducta? Que al fallecer su querido padre en 1816, cuando Echeverría atravesaba el siempre problemático período de la pubertad, un tutor despótico fue puesto a cargo de la familia Echeverría, conforme a las leyes coloniales que aún imperaban en la Argentina independentista. A raíz de ello, Echeverría entra en un estado de rebeldía contra la madre, el tutor y las normas de la sociedad.

Pues bien, las últimas palabras que Echeverría dice escuchar de su madre son las siguientes: "Hijo, yo me muero; la Providencia me llama a su seno... No te olvides de mis lecciones... Eres joven; no te dejes arrastrar por tus pasiones... El hombre debe abrigar aspiraciones elevadas. La Patria espera de sus hijos: ella es la única madre que te queda: A..." (518). Acto seguido, Echeverría emprende un viaje a la "Capital" para mejorar su salud y arreglar: "un litigio de intereses que dejó pendiente mi madre" (520). Desde entonces es perseguido por una voz flotante en carácter de 'superyó': a) al poco tiempo de la muerte de su madre queda angustiado por su ausencia ("El hábito de verla y hablarla me lleva muchas veces a su cuarto: allí está la silla, el sofá, la mesa, la cama; pero todo desierto y silencioso. .." [519, énfasis mío]) y se dirige "como un frenético" a su sepulcro para poder imaginarla mejor; pero es allí que: "una voz apagada [le] responde

9 Consúltese "Psychonalytical Notes on an Autobiographical Account of a Case of Paranoia (Dementia Paranoides)" (1911) de Freud; Crowds and Power (1978) de Canetti; y My Own Private Germany (1996) de Santner.

${ }^{10}$ El poema La guitarra (escrito en 1842 y publicado en 1849) y algunos fragmentos autobiográficos (546, 551) corroboran estos incidentes.

Revista Iberoamericana, Vol. LXXVII, Núms. 236-237, Julio-Diciembre 2011, 953-973 ISSN 0034-9631 (Impreso) 
del seno de la tierra: "Está en el cielo" (519, énfasis mío); b) el mismo patrón se repite cuando va al cementerio: "allí se me presentaron como fantasmas colosales los deslices de mi juventud y me increparon con voces penetrantes mis errores" (520, énfasis mío); c) en la siguiente carta: "Busco a mi madre y no la encuentro, y una voz interior me dice: tú abreviastes sus días. . ." (520, énfasis mío); y d) finalmente en una pesadilla:

[U]n fantasma vino y llenó todas mis facultades: un velo fúnebre cubría su semblante tétrico y descarnado. Sus cóncavos ojos despedían mil flechas que traspasaban mi corazón [...] su vista me devoraba; levantó al fin su ronca voz y me dijo: tu duermes, insensato, tranquilamente, pero llegará la hora en que te sea demandada cuenta de ese reposo; llegará el día en que cada uno de los pesares que ocasionaste a tu madre, cada lágrima de las que la hiciste derramar, entrará con el peso de una montaña en el plato de la culpa. La balanza se moverá entonces y el plato de la redención subirá al cielo y el plato del pecado se hundirá en el abismo. (532, énfasis mío)

Unos días después, su sufrimiento lo lleva a imitar a Werther pero es interrumpido cuando:

[...] una voz exclamó como bajando del cielo: «detente» [...] Entonces, amigo, la eternidad se desplegó ante los ojos de mi fantasía... El cielo... [...] Allí estaba mi madre: miróme con sonrisa dulce y cariñosa y me dijo: [...] El don precioso de la existencia no te fue otorgado para que dispusieses de él a tu antojo, sino para que lo empleases en obras grandes [...] Vive, hijo [...] (537)

De inmediato la salud de Echeverría queda reestablecida. Al poco tiempo acompaña a una ex amiga de su madre, la señora Ana, a una tertulia en donde se enamora de "Luisita C...". En las últimas dos cartas resume la esencia de la evolución de Cartas: "Sólo sé que he sufrido en el curso de mi vida tormentos horribles y saboreado delicias inefables" (540).

\section{LA CONSTITUCIÓN DEL SUJETO FANTASMÁTICO}

Nacer implica pasar del vientre materno al mundo del lenguaje, por lo cual el 'presujeto'-el infante, del latín infans: sin habla-se constituirá no-evolutivamente en 'sujeto' al y del lenguaje qua Otro. Se forma así una relación que anuda al sujeto con el lenguaje y el agujero en el lenguaje (la imposibilidad del lenguaje de totalizar la existencia del sujeto en y con 'la realidad'). De este modo el lenguaje puede presentificarse en una $\mathrm{u}$ otra faz acorde a las circunstancias singulares que constituyen lo inconsciente (del sujeto) en relación a la situación confrontada: su costado simbólico/imaginario (el Otro incompleto) o su cara Real ("un real no simbolizado, a pesar de la forma simbólica" Lacan, Escritos 97) que, justamente, por estar fuera del lenguaje, por ser la quebradura

\footnotetext{
Revista Iberoamericana, Vol. LXXVII, Núms. 236-237, Julio-Diciembre 2011, 953-973
ISSN 0034-9631 (Impreso)
} 
en y del lenguaje, es el vacío en sí, y por ello, por un lado, es el agujero negro alrededor del cual se estructura la realidad simbólica-imaginaria y, por otro lado, a diferencia del incompleto lenguaje, es la completud absoluta.

Lo Real es la ruptura del lenguaje en sí que, en su interioridad, es totalmente lleno de nada; es el vacío cuya vacuidad pura no mantiene diferencias y desniveles dentro de su misma estructura. Mientras que en lo Simbólico e Imaginario la reflexión de sí siempre produce diferencia con respecto a sí mismo, lo Real se presentifica como si ya desde siempre ha consistido de una condición incambiable, eternamente idéntico a sí mismo. Lo Real es entonces lo no-familiar porque es lo a-histórico, aquello imposible de medir semióticamente. Es la sensación de caída al abismo infinito que impide la posibilidad de distinción entre los tramos de la caída; es una perpetua repetición sin diferencia -sin discriminación de temporalidad y espacio- que provoca una angustia arrolladora. Toparse con lo Real implica no poder proyectarse, reflejarse y totalizarse en el Otro; y es esta imposibilidad de representarse en y por el Otro lo causante del efecto angustiante-Real, sentir 'con el cuerpo' la fractura de la reflexión imaginaria-cartesiana.

Este doble efecto del habla en el sujeto deviene de haber atravesado la 'castración simbólica' $(-\varphi)$ de forma "normal" de ser un neurótico. La castración es la introyección del orden diferencial del significante que hizo que el pre-sujeto (S) (el cuerpo en su Real) sea sujeto (\$); que su deseo incestual por su madre sea reprimido en lo inconsciente. La castración constituye-escinde al sujeto de lo inconsciente (su división es su fundación) y produce un fragmento de goce (lo Real) que pasa a ser el motor del deseo del sujeto, el objet petit a (objeto $a$ ). ${ }^{11}$ Así, y en contraste con el episteme historicista-positivista basado en una opositoria relación de 'objetividad' del sujeto autónomo enfrentado al objeto externo del conocimiento (el objeto simbólico-imaginario), el sujeto dividido habita topológicamente-simultáneamente en ambos lugares; es decir, el sujeto 'es' la relación indivisible de 'objetalidad' entre el \$ y el $a$ : el \$ es el a desprendido y, reversivamente, el $a$ es el $\$$. El enlace topológico de $\$$ con el $a$ es la estructura del fantasma $(\$ \diamond a)$.

\footnotetext{
${ }^{11}$ El objeto a no es un objeto material (empírico, simbólico, imaginario, metafísico, etc.) sino la relación pulsional (libido qua energía psíquica sexual) entre las zonas erógenas del sujeto y las especies del objeto $a$ correspondientes (el pecho, las heces, la mirada y la voz). Por ejemplo, el 'objeto $a$-pecho' nombra el goce inconsciente que afecta al sujeto cuando entre los bordes de su boca (la zona erógena constituida como zona de goce por el corte simbólico del significante) y el objeto pulsional pecho (no el pecho empírico y carnal o el pecho imaginado, sino algo ligado a la boca) circula la libido: el pecho es un semblante del objeto a que atrae la pulsión oral del sujeto para que goce en sus labios.

De este modo el pecho no puede ser un objeto-alimento porque, si así fuese, dejaría de haber objeto y pulsión oral una vez incorporado el objeto y satisfecho la necesidad alimenticia. En cambio, si concebimos al pecho como un vacío cargado de fuerza negativa, entonces nunca podrá ser aprehendido; por más que el niño (o el adulto) esté satisfecho alimenticiamente, igual seguirá deseando gozar en los bordes de su boca con un objeto externo cualquiera o inclusive, como se advierte frecuentemente en los bebés, apretando sus propios labios.
}

\footnotetext{
Revista Iberoamericana, Vol. LXXVII, Núms. 236-237, Julio-Diciembre 2011, 953-973
ISSN 2154-4794 (Electrónico)
} 
El objeto a timonea el deseo del sujeto de positivizar su negatividad. Y debido a que el objeto $a$ está ahí afuera, el sujeto (la falta-en-ser) debe insertarse como cuerpo en el terreno Simbólico-Imaginario donde habita el $a$ para unírsele y así presuntamente restituir su falta, volver a ser uno-con-la-madre. O sea que la realidad en sí es fantasmática porque es el escenario que permite realizar el deseo. ${ }^{12}$ Parafraseando a Roberto Harari, el sujeto de la ciencia (todas las teorías historicistas-positivistas) depende de la forma en cómo este cuerpo, envuelto en y por el habla, se proyecta y se sitúa en la realidad, es decir, "es en función del objeto a que un ser hablante puede objetivizar cualquier conocimiento" (Harari 150). Se entiende así por qué la 'objetalidad' está desde siempre operando negativamente como señuelo en la 'objetividad', que es la superficie de las relaciones simbólicas-imaginarias. Entonces, dado que el ' $a$ ' es irreductible -que permanece idéntico así mismo porque es Real-, la estructura del sujeto en su relación al objeto-causa es 'ahistórica'. El efecto del ' $a$ ' en el \$ nunca cambia como estructura de efecto, la repetición de la relación pulsional es inmutable e indestructible.

Ahora bien, en tanto que en la relación fantasmática el objeto a es causa del deseo del sujeto e, inversivamente, el sujeto es objeto del objeto $a$, la realidad del sujeto es siempre de carácter sadista-masoquista: si por un lado la boca del bebé incorpora sadísticamente el $a$-pecho desde afuera hacia adentro, sincrónicamente el pecho está incorporando la boca del bebé desde adentro hacia fuera; el bebé está sado-masoquísticamente 'incorporando-siendo incorporado' por el Otro. Lo crucial entonces es captar el doble y simultáneo lugar que ocupa el objeto a respecto del sujeto: es un objeto de satisfacción que se desea integrar para sí y, a la vez, es un objeto hostil que desea absorber al sujeto

12 El fantasma posibilita que todas las experiencias con el Otro sean vivenciadas de manera no-traumática. Sin la función de filtro del fantasma, la relación con el Otro (el contacto corporal, una conversación, etc.) sería igual de insoportable que previo a la castración simbólica. El fantasma es como la pantalla del televisor que impide que la luz pura que emana desde adentro del aparato caiga a chorros sobre nuestros ojos hasta cegarnos; la pantalla disminuye la intensidad de la luz al convertirla en las figuras sobre la pantalla que, a su vez, captan nuestro deseo y lo regulan. Es en este sentido que, a decir de Lacan, "no hay relación sexual" (no hay una relación directa entre el sujeto y el Otro, no hay dos medias naranjas que forman un perfecto entero; 'no hay relación social') al menos que sea mediada y distorsionada por el fantasma. Si de la realidad se eliminase el fantasma, la realidad simplemente se desintegraría como sucede en las pesadillas. O lo que es igual, si se materializase el fantasma, el \$ se uniría al $a$-Real, por lo cual el \$ sería absorbido por el $a$; como ocurre en muchos suicidios: el \$ se lanzaría por la ventana para sentir lo no simbólico/no-diferencial provocado por la caída libre.

Volviendo a la pesadilla, la razón por la cual todos nos despertamos repentinamente es porque en el sueño nos topamos con una punta de lo Real. Esto prueba que, más allá de la duda que genera no saber lo que realmente acaeció cuando se dormía, lo que sí es verdadero (un fenómeno puro, sin la mediación del lenguaje; es decir, que no engaña) y universal (sin importar el género, la clase económica, la etnia, la posición geográfica o la temporalidad del durmiente) es que hubo algo intolerable en el sueño que impidió el deseo original de dormir en continuo. Esta 'causa' no es otra que lo Real -la nada absoluta (no la imagen del vacío sino la ausencia absoluta de cualquier tipo de imagen o símbolo; el significante en su faz Real)- que nos obliga regresar a la consciencia (a despertarnos) y separarnos de lo Real.

Revista Iberoamericana, Vol. LXXVII, Núms. 236-237, Julio-Diciembre 2011, 953-973
ISSN 0034-9631 (Impreso) 
como en la pesadilla, el lugar de la madre omnipotente que busca gozar con el sujeto, lo que Freud denomina das Ding (la Cosa).

Es precisamente esta última modalidad del $a$-el aspecto Real del fantasma- lo que opera en Cartas: Echeverría narra su sensación de sufrimiento devenida de su 'no-relación' con su madre. Ésta se presentifica en su condición de madre 'siniestra' (unheimlich) para asediar a Echeverría a través de su voz. Algo que era familiar en ella (heimlich) se ha transformado en 'no-familiar' (un-heimlich), foráneo, lo cual no significa enfrentarse a un objeto imaginario-simbólico desconocido sino toparse con algo no-familiar (Real) que emerge del (en el) objeto familiar (Imaginario/Simbólico): es la aparición de aquello que debía permanecer oculto y que brota intempestivamente para fragmentar la unificación imaginaria-narcísica-cartesiana de Echeverría. Éste es el caso de lo siniestro en lo angustiante, el efecto de 'ex-trañamiento' de-en la madre qua Otro que evoca un deseo indescifrable y amenazador. De ahí que en Cartas Echeverría no pueda reconocer la voz de la madre hasta el final.

\section{El objeto A-vOZ en CARTAS}

Y es precisamente la voz el objeto pre-simbólico que, como si fuese la placenta, mantiene unido a Echeverría con su madre en carácter de Otro primordial, Real. ${ }^{13}$

\footnotetext{
${ }_{13}$ Para el psicoanálisis lacaniano la voz no es: a) la palabra, enunciado o habla, mía o de quien me habla; b) la mínima unicidad material del hablante; c) el intento fallido, según diserta Jacques Derrida, de la consciencia de ser auto-afección, de ser una inmediatez interior pura (fallido porque la voz, de acuerdo a Derrida, ya desde siempre está impregnada del trazo de la escritura, de alteridad; para Derrida la condición 'fonocéntrica' de la voz la hace una mera presencia metafísica); d) el vehículo que transporta el significado de la palabra, el mediador para llegar al sentido lingüístico como meta; e) el objeto de la fonética tradicional, fracasada una y otra vez en su intención de desentrañar su producción sonora, sus propiedades físicas y fisiológicas; o f) el objeto de la fonología, enfocada exclusivamente en la voz como fonema y cuyo intento de clasificarla en base a su diferencia fonética (entonación, timbre, acento, etc.) con otros fonemas también falla porque la operación divisoria en sí siempre produce un nuevo resto sin significación (Dolar 13-32).

De hecho, el objeto $a$-voz qua deseo en el Otro es precisamente este residuo de la simbólica escisión sincrónica (diacronía-retracción) que la fonología no puede catalogar. El $a$-voz es 'la falta' en la voz simbólica, la ruptura en el núcleo de la presencia en sí, el invisible vacío cargado de libido que habita en la voz simbólica mía o de otro. El a-voz en la voz simbólica es el 'objeto-causa' de deseo del sujeto de simbolizar la voz-Real; uno es atraído a la voz simbólica -sin importar su sonoridad, intensidad, etc.sólo porque el objeto $a$-voz Real está 'viviendo' en ella, es aquello inaprensible en la voz que es más que la voz: el granito de arena en el centro de la perla.

La voz es producida retroactivamente por la misma enunciación y emerge ya perdida, constituida como perdida, separada del cuerpo del sujeto y del Otro y que resiste a convertirse en significado: el silencio o, contrariamente, el sonido lleno, el grito puro no-significante que marca el oído con erogeneidad. La voz: "no es el sonido sino ese real sin duración que surge borrándose cuando algo es significado por el Otro" (Juranville 151, énfasis mío). Debido a que el lenguaje es el Otro, en el preciso momento en que enuncio yo ya estoy produciendo el objeto $a$-voz que es el resto del Otro como vacío, ya le estoy contestando al

Revista Iberoamericana, Vol. LXXVII, Núms. 236-237, Julio-Diciembre 2011, 953-973
ISSN 2154-4794 (Electrónico)
} 
La voz se presentifica como el superyó maternal, arcaico, que retorna desde lo Real para martirizar al sujeto como sucedía previo a la castración simbólica. Entonces, cuando el infante todavía estaba vacío de lenguaje, la voz que acompañaba el período de lactación era percibida como siniestra, ya que la enigmática madre, censuradora y regocijante, no podía ser significada con la medida justa. La voz escuchada eran meros ruidos sin coherencia alguna, entrecortados, imperantes y fusionados a las intercaladas vivencias de su presencia y ausencia. Era una voz que invadía gocísticamente su cuerpo y que él desconocía su origen porque no la podía ver (de hecho, nunca se puede ver la cavidad del estómago desde donde proviene la voz). Y siendo una voz flotante, desprovista de su cuerpo-fuente, se presentificaba como autónoma, como un 'órgano sin cuerpo' ${ }^{14}$

Pero cualquier voz que se ve que emana de un cuerpo humano también está revestida de una cualidad siniestra porque la voz es aprehendida ya separada e independiente del cuerpo y por eso ya desde siempre es poseída con un mínimo grado de ventrilocuismo, como una voz espectral (Žižek, On Belief 58). No obstante, cuando el cuerpo desde donde brota la voz está ausente, como sucede en Cartas, la voz alcanza un efecto más siniestrante en el oyente Echeverría.

La voz impersonal, suspendida, que castiga a Echeverría, está como envainada de una cualidad divina: a) omnipresente, porque parece provenir de todos los lugares y estar en todos los lugares, y b) omnipotente porque, al no estar fijada a un cuerpo, cobra la fuerza que deviene de su autonomía, está redoblada en fuerza. La voz dotada de autoridad condiciona a Echeverría a oírla, y por el mero hecho de escucharla, está comandando su dominio sobre él. Lleno de angustia, Echeverría es esclavo de la voz-amo, aunque, paradójicamente, porque la voz es imprecisa, nunca sabe si está cumpliendo correctamente el mandato. La intervención de la voz lo desorienta y lo llena de culpa

Otro con mi fantasma (Žižek, "I Hear You" 90). Es decir, la voz es el hueco en la voz simbólica que es la presencia del Otro previa a mi enunciación: el agujero entre lo que yo hablo y lo que se constituye como anterior a mi habla, con y por mi habla, es la presencia espectral de la voz. Se goza inconscientemente cuando la voz circula alrededor del borde palpitante del oído, cuando su entrada y salida del oído atrae el deseo que repta en la pulsión invocante. Žižek da un buen ejemplo de la aprehensión del objeto $a$-voz 'constituyéndose' retroactivamente a partir del significante: "when the same word is repeated to us indefinitely we become disorientated, the word loses the last traces of its meaning, all that is left its inert presence exerting a kind of somniferous hypnotic power-this is the voice as 'object', as the objectal leftover of the signifying operation" (Žižek, Sublime Object 104); es decir, la constante repetición de la castración simbólica materializa al $a$-voz como objeto pulsional, desalojada y aislada del significante simbólico.

${ }^{14}$ La voz superyoica vuelve a evocar la experiencia de la etapa primaria porque comanda sin precisión; es un mandato puro (el significante en su faz Real) como los primeros gritos escuchados por el recién nacido. Es arbitraria e irracional: a) cruel porque demanda imposibles en vista que el $a$-voz es inaprensible; b) sadística porque se burla de sus incumplimientos y goza de ello; y c) obscena, ya que al ser pre-simbólica, es sexual. En suma, la voz no es la instancia moralista que exige el cumplimiento de la ley, sino el acatamiento a escuchar la imposibilidad de su deseo (Lacan, Ética 369).

Revista Iberoamericana, Vol. LXXVII, Núms. 236-237, Julio-Diciembre 2011, 953-973
ISSN 0034-9631 (Impreso) 
cada vez más porque la voz no es la instancia kantiana, la enunciación pura que uno debe completar con el enunciado, sino que es, como teoriza Dolar:

[...] a moral agency in relation to which we are always deficient: however hard we try, we will always fall short, and the more we try to live up to it, the bigger the gap. It is a voice that always reduces the subject to guilt, and the guiltier we are the guiltier we will become, in a self-propelling process; we even relish our self-reproaches and our failures. (99)

Es por eso que cuanto más obedece Echeverría al deseo de su madre, más culpable se siente de no estar satisfaciéndola. Más aún, sus constantes autorreproches a su vez traslucen que: a) goza de su culpabilidad (si no gozara, no habría mea culpa) y b) la voz lo está poseyendo; lo hace repetir el fracaso de la imposibilidad de alcanzarla, según lo expone la mimesis del discurso. Por ejemplo, primero Echeverría se culpa: "[Y]o abrevié los días de mi desventurada madre; mis desaciertos le ocasionaron aquella melancolía profunda que la consumió; yo robé al mundo aquella vida tan preciosa empleada toda a socorrer al desvalido y en aliviar la humanidad doliente" (520, énfasis mío) y de inmediato la voz le increpa: "tú abreviastes sus días. .." (520, énfasis mío).

La voz flotante evoca a su madre muerta. No es la voz de su madre cuando estaba en vida, la voz familiar, sino la voz siniestra no-familiar que al no estar apegada a un cuerpo trastoca la percepción imaginaria que Echeverría tiene de la voz de la madre unida a su cuerpo. Este extrañamiento carga a la voz simbólica de un plus (plus-de-jouir) que torna a la voz en angustiante y fascinante; y, como tal, poderosa, fálica, que lo hace gozar (si no tuviese poder sobre él, simplemente no la obedecería): la voz presentifica súbitamente la inconmensurabilidad del falo en su versión fónica.

Entonces, la pesadilla de la calavera es la madre muerta que retorna como voz fantasmagórica para recriminarle a Echeverría sus errores. La relación entre la voz de la madre y la voz de la calavera es más que evidente: primero adelanta que cuando la madre: "articula algunas palabras, el cansancio y la fatiga las ahogan entre sus labios" (518, énfasis mío), luego que ella deja a medias su consejo diciendo: "La Patria espera de sus hijos: ella es la única madre que te queda: A . .." (518, énfasis mío); y, a continuación, que: "[...] la palabra expiró en su garganta y la expresión de su fisonomía y de sus ojos me dijeron el resto con voz callada y elocuente" (518, énfasis mío). Efectivamente, la voz de la madre en su estado puro queda atragantada en la boca del significante y fracasa en brotar hacia afuera para convertirse en voz simbólica, como si la madre se resistiera a cortar el cordón umbilical con Echeverría.

La imagen de la madre muda ocupa el lugar de la voz que, al hacerlo, redobla el efecto de la voz; la imagen es angustiante porque, precisamente, representa visualmente el $a$-voz, como si la imagen estuviera vivificando a la voz, adjudicándole una mayor dimensión y aumentando la angustia de Echeverría ante esta voz hinchada en fuerza

Revista Iberoamericana, Vol. LXXVII, Núms. 236-237, Julio-Diciembre 2011, 953-973 ISSN 0034-9631 (Impreso) 
que se acerca peligrosamente hacia él: "[...] aquella idea fatal me sorprende en medio de halagüeñas imágenes, me oprime la garganta como un espectro odioso" (536, énfasis mío). La voz espectral, que Michel Chion define como voix acousmatique en su clásico La voix au cinéma (1982), es justamente esta voz persecutoria que retorna como superyó malévolo; la voz atragantada retorna desde y en lo Real como sonido vacío que resuena en él: "todo desierto y silencioso", "voz callada", "voz apagada", "voces penetrantes", "voz interior" y en la "ronca voz" de la calavera. Y que de hecho, reaparecerá repetitivamente en "El matadero" (la voz que personifica la ausencia de Rosas y la voz entrecortada según señala la nota $8 \mathrm{~B}$ ) y en La guitarra (la voz de la conciencia que culpa al personaje Ramiro por haber matado al esposo de Celia, el personaje que representa a la mujer casada con la que Echeverría tuvo una relación sentimental).

Pero, ¿por qué retorna la madre a través de la voz o la mirada? ${ }^{15}$ Porque, como se adelantó, hay algo traumático en la relación madre-hijo que permaneció inconcluso (reflejado en el hecho que Echeverría va a la Capital por "un litigio de intereses que dejó pendiente mi madre"), aunque no porque haya habido un conflicto o un resentimiento consciente de uno hacia el otro, de manera unilateral o recíproca. Sucede que Echeverría desplaza-deforma su fantasma fundamental singular (sea cual fuere) a una 'no-relación' con su madre por y con los incidentes de su muerte; con el fallecimiento de la madre su fantasma se reconstituye retroactivamente y 'diferidamente' como novela familiar alrededor de una no-relación con su madre en términos de haber sido "parido en forma no de todo honrosa", de la desacreditación de su honra "en función de su origen, de su antecedencia materna" (Harari 209). ${ }^{16}$ Así, el adolescente Echeverría se rebela contra la madre porque, en su realidad psíquica, ella es responsable de que el tutor deshonre el Nombre-del-Padre y por ende que Echeverría termine estigmatizado y humillado ante la sociedad: él es 'un mal parido' porque el deseo de su madre lo bastardizó. Dado que padre e hijo, a partir de su apellido, comparten una identidad que los une, la denigración del esposo recae por igual sobre Esteban. He ahí que la previa reflexión de Echeverría en su ascendiente paterno sufre un disloque que perturba su imagen fálica.

Por eso es consecuente que, desde la lógica psicoanalítica, la conducta de Echeverría haya sido un fiel reflejo de su percepción de la madre: ¿no es establecer una relación con una mujer casada o frecuentar lugares de poca reputación la materialización del fantasma de la deshonra, de difamar el apellido familiar? Al revés, la positividad de las acciones de Echeverría está revelando que habrá existido una causa negativa que lo gestó: las acciones de la madre. O sea que lo que Echeverría supuestamente aborrece en su madre es aquello con lo cual se ha identificado; así, en vista que el deseo del sujeto es siempre el deseo del Otro, el deseo de la madre está inscripto negativamente en las

${ }_{15}$ En otro ensayo en preparación, analizo el objeto a-mirada en la pesadilla de la calavera.

${ }^{16}$ Enfatizo: 'diferidamente' porque la retroconfiguración de su fantasma sobreviene no cuando muere su madre sino cuando redacta Cartas diez años después.

ISSN 0034-9631 (Impreso) 
acciones de su hijo. En tal sentido, el deseo en/de la madre qua objeto $a$ es el núcleo que hace de soporte de su fantasmatización masoquista; es decir, él está poseído por el agujero negro que es su no-relación con ella.

Este es un punto crucial que marca la diferencia conceptual respecto de los acercamientos 'historicistas-foucaultianos': no es que la madre sea el agente externo e independiente que 'construye-disciplina' al objeto Echeverría -que el retorno de la madre como voz está desestabilizando la relación de Echeverría con el Otro, su identidad imaginaria como reflejo del Otro-, sino que le da forma al trauma que ya habitaba en Echeverría, al obstáculo que es en sí la inherente no-relación sexual con el Otro y que puede o no devenir de un encuentro con lo Real en la madre. ${ }^{17}$ En otras palabras, la distorsión traumática-fascinante en la madre no es de ella sino suyo, y por eso sólo él la reconoce inconscientemente en el lugar de la madre; él es afectado por el fragmento Real porque es su fantasma. Parafraseando a Žižek, la madre no reprime la relación sexual de su hijo sino que la materializa, la obstaculiza con una piedra de demasiado goce (Žižek, Enjoy 128). La voz-superyó es este bloque obturador que le ordena a Echeverría a gozar violando la ley: ¿y no es su intento de suicidio el desacato de la ley, la huída de lo Simbólico para cruzar al mundo de lo Real?

Me explico: Echeverría ficcionaliza la no-relación sexual como 'la no-relación con su madre' y lo que cumple la función de este impedimento qua superyó es el último deseo de su madre antes de morir: "La Patria espera de sus hijos: ella es la única madre que te queda: A..." (518). La madre impuso un pacto con su hijo -la substitución de ella por la madre patria-y cualquier desviación de brindarse por completo a los ideales patrióticos implicaría violar un compromiso que tiene el peso de un mandamiento. El superyó es esta "voz de la razón" (Echeverría 517) -la voz kantiana del deber en nombre del bien moral colectivo-que se ha desviado de su trayectoria, que ha avanzado demasiado por la banda de Moebius hasta convertirse en la destrucción de la ley, que le exige a Echeverría su entrega incondicional; en su afán por satisfacer el deseo de su madre, Echeverría termina atravesando al lado opuesto de la banda, al reverso de su subjetividad simbólica.

No es que el superyó le esté ordenando ad verbatum que se suicide, sino que la imprecisión de la voz flotante, que no es un mandato claro sino puras injurias que lo llenan de culpa y no ofrecen la posibilidad de reivindicación o redención, destruye el deseo qua ley al inyectarle demasiado goce hasta hacerlo implosionar. El superyó es sadístico porque lo obliga a un imposible: gozar absolutamente todo el tiempo. La repetición de su fracaso de satisfacer plenamente el deseo de su madre-de restituirle su voz perdida- lo carga de culpa. Y esta culpa asociada a la condición siniestrante

${ }_{17}$ En El fantasma de Esteban Echeverría (2010) proporciono una elaboración más extensa sobre el punto ciego de las interpretaciones fenomenológicas-historicistas.

Revista Iberoamericana, Vol. LXXVII, Núms. 236-237, Julio-Diciembre 2011, 953-973
ISSN 2154-4794 (Electrónico) 
que es la repetición per se, de que algo se repite y no puede detenerse, es aquello que expande desproporcionadamente su tensión psíquica. O sea que el superyó materno no le prohíbe gozar a Echeverría sino, al revés, le impone la obligación inapelable de que goce y, a la vez, castiga su fracaso de manera más cruel a través de la angustia. Y esta tensión psíquica es de tal magnitud que a Echeverría no le queda otra alternativa que salirse del mundo del lenguaje y la ley.

Sin embargo, como su intento de suicidio es sólo un fantasma de suicidio, su aparente melancolía también participa de esta escenificación. De ahí que la correspondencia de su seudo melancolía con el intento de suicidio está ligado a la calavera en la pesadilla en su estatuto de: a) imagen de la muerte (la degradación de su madre moribunda hacia su forma esquelética final) y b) objeto $a$-mirada qua muerte del sujeto cartesiano Echeverría: que en su pesadilla Echeverría haya raspado el objeto $a$-Real en lo visual (la calavera) ya anticipaba su identificación absoluta con el objeto $a$ de su suicidio melancólico. Al identificarse con la calavera, Echeverría se une al resto de la madre muerta, que es 'la nada' en lo Imaginario-Simbólico, el objeto $a$; he aquí que, por un instante, Echeverría queda anonadado.

\section{EChEVERría 'ES' la CAlavera QUA DAS DiNG}

Pero la monstruosidad de la calavera no está 'significando' al superyó materno que le prohíbe la relación sexual a través de su consejo de sublimar el deseo sexual en pos de los ideales revolucionarios, que condena eternamente el deseo de su hijo a los límites de la patria, único objeto posible de suplantarla. Tampoco es la 'simbolización' de este impedimento o cumple la función de obstructora. La calavera qua das Ding es pura y exclusivamente el mismo Echeverría como das Ding; es el negativo de su identidad simbólica-imaginaria, vaciado de su historia simbólica. Hay algo en Echeverría 'más que Echeverría' que emerge aquí como objeto $a$ en forma de voz y mirada que se presentifica como la calavera y que realiza el reencuentro con su goce perdido, la positivación de su singular castración: la calavera es la figura que adquirió la monstruosidad del deseo incestual por su madre al ser expedido hacia fuera. ${ }^{18}$

La calavera evidencia que un fragmento no-familiar lo descentró de su posición cartesiana, interrumpió el correr de su deseo y causó la formación simbólica-imaginaria del espectro de la madre. Muestra que en el tiempo de Cartas-La cautiva-Dogma_"El matadero" su fantasmatización estaba determinada por su no-relación a nivel estructural con su madre presentificada a través de la mirada y la voz qua distorsiones anamorfósicas: la calavera de ojos huecos que no ven y de boca sin lengua que no habla es su propia

${ }^{18}$ Consúltese el capítulo seis de The Interpretation of Dreams (1900) de Freud.

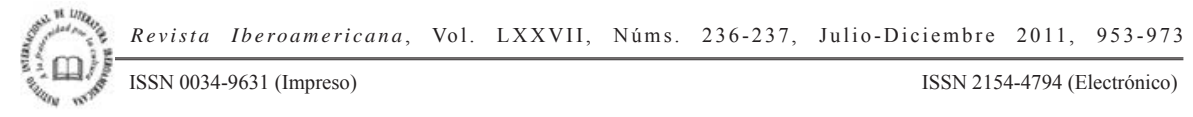


externalización de la mirada y la voz que, conscientemente, no desea ver o escuchar en su realidad efectiva.

Pero, ¿por qué no se suicidó? Porque se puso en acto la castración y el deseo de la madre quedó simbolizado. En el momento que iba a dispararse, una voz "como bajando del cielo" (537) le ordena "detente" (537), y esta voz ya no es la siniestrante voz flotante, sino la voz asociada al cuerpo desde donde procede: el cuerpo de la madre. En efecto, cuando en su "fantasía" (537) Echeverría recibe el consejo final de su madre desde el cielo (como acontece en el episodio bíblico de Abrahán): "Vive, hijo, como has vivido y hallarás algún día la felicidad" (537), se está simbolizando la escena traumática inicial de la madre agónica (518), cuando la voz atragantada dejó incompleto ese primer consejo y propulsó a Echeverría a completarlo con su subjetividad, ;que es el fantasma Cartas! La intervención desde el cielo pone fin a la incertidumbre del deseo y Echeverría es liberado de su trauma persecutorio en forma de voz fustigadora; la madre siniestra en cuyo semblante Echeverría creyó leer su "acusación" y su "martirio" (518) ha revertido a su posición de madre bienhechora, "de sonrisa dulce y cariñosa" (537), la madre idealizada.

Al revelarse como el origen de la voz, ella pierde su fascinación y poder que devenía justamente de su ocultamiento; deja ver que detrás de su velo no hay nada fascinante. La fascinación no era causada por lo que estaba detrás del velo, sino por el velo en sí que la recubría y actuaba como señuelo para el deseo de Echeverría. El semblante $a$-mirada de la madre en función de velo lo fascinaba y angustiaba porque incrementaba la tensión psíquica de su castración simbólica. Pero, al caer la máscara también cae, como una guillotina, la castración. Y así, por ser desenmascarada, cesa la fascinación angustiante en el campo sonoro y visual. Por eso leemos que de inmediato Echeverría confirma el fin de su trauma: "Salí de mi letargo, mis sentidos se recobraron y mi corazón está tranquilo como nunca" (538). Desde entonces la madre siniestra es simbolizada hasta el final, lo cual queda corroborado cuando acompaña a Ana (señora "muy respetable" y "antigua amiga de [su] madre") al baile donde conoce a Luisita.

\section{Conclusión: La Simbolización DE DAS DinG}

Al poco tiempo de llegar a la fiesta, la anfitriona le comunica a Echeverría que "Usted ha venido en mal día [...] nuestra tertulia está hoy algo triste; falta el alma de nuestra reunión, la señorita Luisa C..." (538). Y enseguida uno de los concurrentes agrega: “¿Qué, no vendrá Luisita? [...] Se hace hoy desear mucho”(538). La propietaria continúa ensalzando a Luisita: "[...] esa señorita es el ornamento más lucido de esta sociedad por su carácter amable y bondadoso, y por su talento, gracias y jovialidad [...] cuando no viene me parece que falta algo en la casa [...]" (538). Y en vista de la fama que Luisita acarrea, Echeverría se muestra muy interesado en conocer a esta persona tan deseada.

\footnotetext{
Revista Iberoamericana, Vol. LXXVII, Núms. 236-237, Julio-Diciembre 2011, 953-973
ISSN 2154-4794 (Electrónico)
} 
Contra todos los pronósticos, Luisita sí llega a la fiesta y "Toda la reunión se puso en movimiento [...] varios jóvenes se adelantaron a saludarla" (539). La dueña le da la bienvenida y comenta: "Te has hecho desear mucho esta noche; nuestros concurrentes estaban inquietos por ti y aun este caballero, nuevo en esta sociedad, ha participado del interés que todos han manifestado, pues te creíamos enferma" (539, énfasis mío). Después de esta introducción, Echeverría establece una conversación con Luisita que termina sellando definitivamente su flechazo por ella: "La pureza de su corazón resplandecía en sus negros ojos $[\ldots]$ una especie de fluido magnético, saliendo de toda su persona, se derramaba suavemente por todos mis sentidos y potencias y los encadenaba" (539).

Es obvio que Echeverría ha superado (en Cartas) su trauma, ya que su deseo no es más presa del deseo de la madre siniestra (de lo Real del deseo) sino de su madre familiar (de lo Simbólico del deseo) que Luisita representa perfectamente. Al igual que sucedió con la intervención desde el cielo, Luisita también aparece inesperadamente en la "triste" fiesta para purgarla de la inhibición devenida de la falta de deseo de sus invitados; es decir, la castración simbólica de la madre desde el cielo es redoblada por Luisita en posición de falo que todos desean. Las caracterizaciones de Luisita como "alma de nuestra reunión" le confieren a ella una posición privilegiada en la estructura y por eso su presencia en la tertulia vuelve a poner en marcha el corrimiento del deseo colectivo en torno a ella qua falo.

Consecuentemente, porque Luisita decide apegarse a Echeverría -desea el deseo de Echeverría-, ella termina fortificando la imagen fálica de Echeverría. Si al principio de la fiesta Echeverría era un hombre carente de significado ante los invitados: "[...] la concurrencia era muy numerosa [...] Cuchicheaban en secreto de cuando en cuando, y me parecía que se decían al oído: ¿quién será este hombre tan frío y taciturno?” (538, énfasis mío); una vez que se asocia a Luisita, este vacío pasa a ser toda fascinación para los espectadores presentes. Empero, Luisita continúa teniendo el falo para Echeverría y los demás pero, por el hecho que ella se decidió por Echeverría y no por otro, la imagen fálica de Echeverría queda enaltecida ante la mirada del Otro: "La vista de los circunstantes seguía embebida en nuestros rápidos movimientos [...]" (539, énfasis mío).

Luisita qua falo divide la relación de Echeverría con su madre muerta y lo distancia de la mirada y voz qua das Ding; ella restaura la castración simbólica que 'priva' a la madre de tomar al hijo como el falo y le prohíbe a Echeverría de tomar a la madre como el falo. Por eso, ella personifica a la madre idealizada de Echeverría: primero es informado de su carácter "amable y bondadoso" y luego se menciona que la creían "enferma". Es como si la madre familiar hubiese descendido desde el cielo para terminar de simbolizar la no-relación que había comenzado con su "detente"; como si se hubiera revestido de una Luisita jovial y "angelical” (539) para asegurarse de no ser una interposición sino un puente entre su hijo y una mujer no-prohibida (Luisita no está casada).

\footnotetext{
Revista Iberoamericana, Vol. LXXVII, Núms. 236-237, Julio-Diciembre 2011, 953-973
ISSN 2154-4794 (Electrónico) 
Esta no-prohibición se advierte en la previa descripción del semblante de Luisita, el cual dista bastante de ser el semblante melancólico y enigmático de la madre enferma que angustiaba a Echeverría. Ahora, al estar con Luisita, Echeverría busca la mirada de su madre encarnada en la señora Ana para recibir de ella su bendición, para satisfacer el deseo de que su hijo abrigue "aspiraciones elevadas", como si al juntarse con Luisita, el "ornamento más lúcido de esta sociedad", Echeverría hubiese finalmente "comprendido" el consejo de su madre y así superado (atravesado) lo Real de su fantasma, para así, salutíferamente, volver a fantasmatizar la relación sexual.

\section{ObRas CITADAS}

Alberdi, Juan Bautista. Bases y puntos de partida para la organización política de la República Argentina. Buenos Aires: Centro Editor de América Latina, 1979.

Amante, Adriana. "La crítica como proyecto. Juan María Gutiérrez". Historia crítica de la literatura argentina. Noé Jitrik, dir. Vol. 2. Buenos Aires: Emecé, 2003.

Bustos Domecq, Honorio [Jorge Luis Borges y Adolfo Bioy Casares]. "La fiesta del monstruo”. Obras completas en colaboración. Buenos Aires: Emecé, 1979.

Canetti, Elias. Crowds and Power. Carol Stewart, trad. Nueva York: Seabury P, 1978.

Chion, Michel. La voix au cinéma. París: Editions de l'Etoile, 19982.

Copjec, Joan. Read My Desire, Lacan Against the Historicists. Cambridge, MA: MIT $\mathrm{P}, 1994$.

Dolar, Mladen. The Voice and Nothing More. Cambridge, MA: MIT P, 2006.

Echeverría, Esteban. Obras completas. Buenos Aires: Antonio Zamora, 1951.

Páginas autobiográficas. Natalio Kisnerman, ed. Buenos Aires: Eudeba, 1962.

Freud, Sigmund. The Standard Edition of The Complete Psychological Works of Sigmund Freud. James Strachey, trad. 24 vols. Londres: Vintage House, 2001. "A Child is Being Beaten". 1919. Standard Edition vol. XVII. 177-204.

"Constructions in Analysis". 1937. Standard Edition vol. XXIII. 256-69.

"Leonardo da Vinci and a Memory of his Childhood". 1910. Standard Edition vol. XI. 59-137.

"Psychonalytical Notes on an Autobiographical Account of a Case of Paranoia (Dementia Paranoides)". 1911. Standard Edition vol. XII. 3-88.

The Interpretation of Dreams. 1900. Standard Edition vols. IV y V.

"Writers and Day-Dreaming". 1908. Standard Edition vol. IX. 142-53.

Goethe, Johann Wolfgang. The Sorrows of Young Werther. Burton Pike, trad. Nueva York: Random House, 2004.

Harari, Roberto. El seminario «La angustia», de Lacan: una introducción. Buenos Aires: Amorrortu, 1993.

Juranville, Alain. Lacan y la filosofía. Irene Agogff, trad. Buenos Aires: Nueva Visión, 1992.

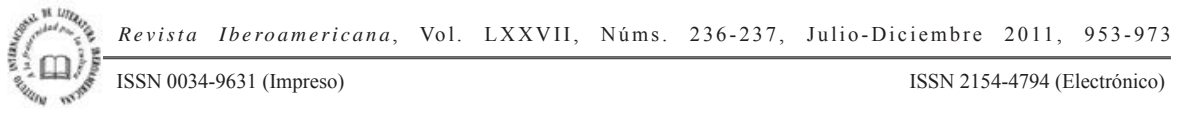


Lacan, Jacques. La angustia 1962-1963. El Seminario de Jacques Lacan. Libro 10. Jacques-Alain Miller, ed. Enric Berenguer, trad. Buenos Aires: Paidós, 2006.

La ética del psicoanálisis 1959-1960. El Seminario de Jacques Lacan. Libro

7. Jacques-Alain Miller, ed. Diana Rabinovich, trad. Buenos Aires: Paidós, 2000. Los escritos técnicos de Freud 1953-1954. El Seminario de Jacques Lacan. Libro 1. Jacques-Alain Miller, ed. Rithee Cevasco y Vicente Pascual, trads. Buenos Aires: Paidós, 1981.

Lamartine, Alphonse de. Ouvres poétiques complètes. París: Gallimard, 1963.

Lamborghini, Osvaldo. "El niño proletario". Sebregondi retrocede. Buenos Aires: Noé, 1973.

Myers, Jorge. "Un autor en busca de un programa: Echeverría en sus escritos de reflexión estética". Las brújulas del extraviado. Para una lectura integral de Esteban Echeverría. Alejandra Laera y Martín Kohan, comps. Rosario: Beatriz Viterbo, 2006.

Sábato, Ernesto. Sobre héroes y tumbas. Caracas: Biblioteca Ayacucho, 1986.

Santner, Eric. My Own Private Germany. Princeton: Princeton UP, 1996.

Sarlo, Beatriz y Carlos Altamirano. "Esteban Echeverría el poeta pensador". Ensayos argentinos. De Sarmiento a la vanguardia. Buenos Aires: Ariel, 1997.

Sarmiento, Domingo Faustino. Facundo. Nueva York: Doubleday \& Company, 1961.

Schreber, Daniel Paul. Memoirs of my Nervous Illness. New York: New York Books, 2000.

Sorbille, Martín. El fantasma de Esteban Echeverría en los orígenes de la modernidad. Escenas y proyecciones sadomasoquistas. Buenos Aires: Biblos, 2010.

Žižek, Slavoj. Enjoy Your Symptom! Jacques Lacan in Hollywood and Out. Nueva York: Routledge, 2001.

"I Hear You with My Eyes; Or, The Invisible Master". Gaze and Voice as Love Objects. Renata Salecl y Slavoj Žižek, eds. Durham: Duke UP, 2000. On Belief. Nueva York: Routledge, 2001. The Sublime Object of Ideology. Londres: Verso, 1989.

Revista Iberoamericana, Vol. LXXVII, Núms. 236-237, Julio-Diciembre 2011, 953-973 
